\title{
Visual Knowledge Underlying Letter Perception: Font-Specific, Schematic Tuning
}

\author{
Thomas Sanocki \\ University of South Florida
}

\begin{abstract}
The representation of visual information about letters is proposed to be highly systematic, involving not only abstract information that is invariant across type faces (or fonts), but also a number of parameters whose values are determined by the current font The system exploits regularities that are characteristic of letters and fonts by becoming tuned to the detals of the font This should result in efficient letter perception when the stimuli are regular (when all of the letters are of a consistent font), but not when the stımuli are irregular (when the letters are from a variety of fonts) The prediction of faster processing with a regular font, as compared with a mixed font, was examined in three experiments requiring the recognition of four-letter strings Experiment 1 confirmed the prediction, and Experiment 2 replicated the effect with the number of "features" equated across conditions. Experiment 3 showed that the disadvantage for a mixture of fonts is related to how much the representational system must be adjusted to handle the different fonts
\end{abstract}

A central issue in cognitive and perceptual psychology is how familiar objects are represented and perceived. This article concerns the representation and perception of letters, which are representative of more complex objects in that they vary considerably in appearance from instance to instance: The actual form of a letter depends on the type face, or font. Therefore, it is necessary for models of letter perception to specify how the perceptual system maps letters of different fonts onto the appropriate abstract letter codes. The purpose of the present research was twofold. first, to begin developing a new kind of model of letter perception, one that uses the idea of a structural network, and, second, to test this model against a class of simpler models by examining how perceptual representations might become systematically tuned for a partıcular font.

A useful general approach to the recognition problem is to assume that letters are represented and perceived as sets of features (e g , Estes, 1978; Gibson, 1969; Keren \& Baggen, 1981; Massaro \& Schmuller, 1975; McClelland \& Rumelhart, 1981; Oden, 1979; Townsend \& Ashby, 1982). In general, this type of model involves a set of detectors that respond to certain features and a set of letter units that receive the outputs from the feature level. There are several different ways in which feature models might handle the recognition problem, depending on the type

This article represents major portions of a PhD dissertation submitted to the University of Wisconsin Portions of these data were presented at the Midwestern Psychological Association Meetıng, May, 1985

The research was supported by National Science Foundation Grant BNS 80-14316 to Gregg Oden

I gratefully acknowledge my advisor, Gregg Oden, for years of thoughtful tutelage and for many invaluable comments on this research I also acknowledge the helpful comments of the other thesis committee members-Wilıam Epsteın, Art Glenberg, Jola Jakımık, and Leonard Uhr-and of Dom Massaro

Correspondence concerning this article should be addressed to Thomas Sanocki, the Department of Psychology, University of South Florida, Tampa, Florida 33620 of model. Here, a crucial distınction is between simple feature models and more complex, network models. In simple feature models, there is a small set of feature units, and they work independently of each other, with no interconnections between units (e.g., Keren \& Baggen, 1981; Townsend \& Ashby, 1982, Tversky, 1977). On the other hand, network models can have a rich and perhaps systematic network of interfeature relations, allowing the models to predict certain systematic constraints on letter perception.

Whether or not a simple feature model can handle the recognition problem depends on the type of features assumed Features could be abstract relations that are "invariant" from font to font (e.g., Gibson, 1969). In such an abstract feature model, the feature detection process is assumed to filter out the many details that characterize a particular font and to extract essential information that is true across fonts. In principle, such a model provides a solution to the recognition problem However, it is difficult to specify exactly what the features are, and it is not clear how such feature detectors might work Feature detectors that work on letters from a variety of fonts have rarely (if ever) been demonstrated

In the second type of simple feature model, the features are specific parts of specific fonts (e g, Rumelhart \& Siple, 1974; Townsend \& Ashby, 1982) It seems easier to Imagine how fontspectfic detectors might work; for example, they could match simple feature-templates However, a problem with this type of model is that the set of features for one font is not necessarily appropriate for another font (cf. Gilmore, 1985); therefore, it is not clear how letters are represented and perceived across fonts.

Network models can allow for a richer description of the stımulus because features are represented within structural networks (e.g., Minksy, 1975, Oden, 1979; Palmer, 1977; Sanockı, 1986a). A new network model is proposed here, together with a prediction of a new type of constraint on letter perception.

\section{Descriptions Model}

An important property of networks in general and the descriptions model in particular is that an object's description can 
STROKE(hor. position, vert. square)

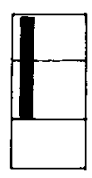

(left, top, central)

LOOP(vert. square, begin, end)

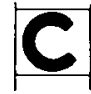

(central, 90, 180)

BAR(vert. square)

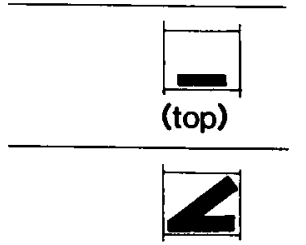

(270)

DOT

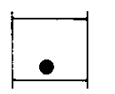

Figure I Each attribute's name (in capitals) and arguments (in parentheses), together with an instance of the attribute, with arguments below (Vertical [vert] position is specified as one of the rectangular regions [top, central, bottom] that contain letter parts Horizontal [hor] position is specified within a region [left, right, or middle], and position on the perimeter of the region is specified in degrees $\left[0^{\circ}-360^{\circ}\right]$ )

be divided into distinct levels or components. The description of a $b$. for example, might include a superordinate unt that represents the letter and that points to units for parts, which in turn point to units that specify properties such as size and shape. Crucially, letters within a type font are systematically related to each other-they have similar shapes and details and systematically related stzes. These relations can be exploited in a network model: A specification of one letter's properties can apply to the other letters within the font as well.

The present model includes an abstract, "deep" level of infor" mation that is true of letters across most typical type fonts, as well as surface levels that specify properties of letters within a particular font The deep-level information is generally fixed, whereas the surface levels are programmable, being determined on-line during experience with a font. The system will first be described from a top-down viewpoint, and then the bottom-up processing of letters will be addressed.

\section{Representational System}

The system involves three distinct types of information. The first type, the deep level font-invanant information, involves abstract units that correspond to generalized parts, or attributes, of letters. The other two types of information are determined on-line One of these types of information is a set of font parameters that describe properties of the font. The third and final type of information is about particular instances of letters. This later information results from transforming the font-1nvariant attributes in accordance with the (font-specific) font parameters

The font-invariant representations of letters are in terms of conjunctions of attributes In the present model, there are five attributes for the lowercase alphabet In Figure I the attributes are named, and one instance of each attribute is illustrated The attributes vary from letter to letter in relative position and in "extent" (how much of the attribute is included). For example, loop and stroke occur in $b, d$, and $f$, but the stroke is on the left of $b$, middle of $f$, and right of $d$, the looped ascender of $f$ is circular but less complete (less extensive) than the loops that are the bodies of $b$ and $d$ The representation of $b$, as an example, would be "has a STROKE [position, extent] and a LOOP [position, extent]" A representation of each letter is listed in Sanocki (1986a).

The instantiation of attributes as a partıcular letter can be described as a transformation from an abstract entity into a description of an actual form. The transformation process has several steps, each controlled by one type of information (e.g., attribute size, attribute shape, and line quality). This information is general across the font and is represented by font parameters. The transformations result in a set of sensory properties that can be matched against sensory analyses. For purposes of llustration, we can assume that sensory analyzers are quite sımple-a retinotopic array of units that indicate "figure" or "ground" for a small stimulus region. Figure 2 illustrates the transformation process for two letters.

Note that the transformations shown in the figure are similar for the two letters. Importantly, the same transformations apply to all letters within a font. In this way, the system exploits regulanties of a font, producing nch descriptions economically Also note that if the font parameters were changed (1.e, if the font were different), quite a different set of sensory properties would result. Yet the same general transformations would take place, and the transformations for different letters within the font would be similar

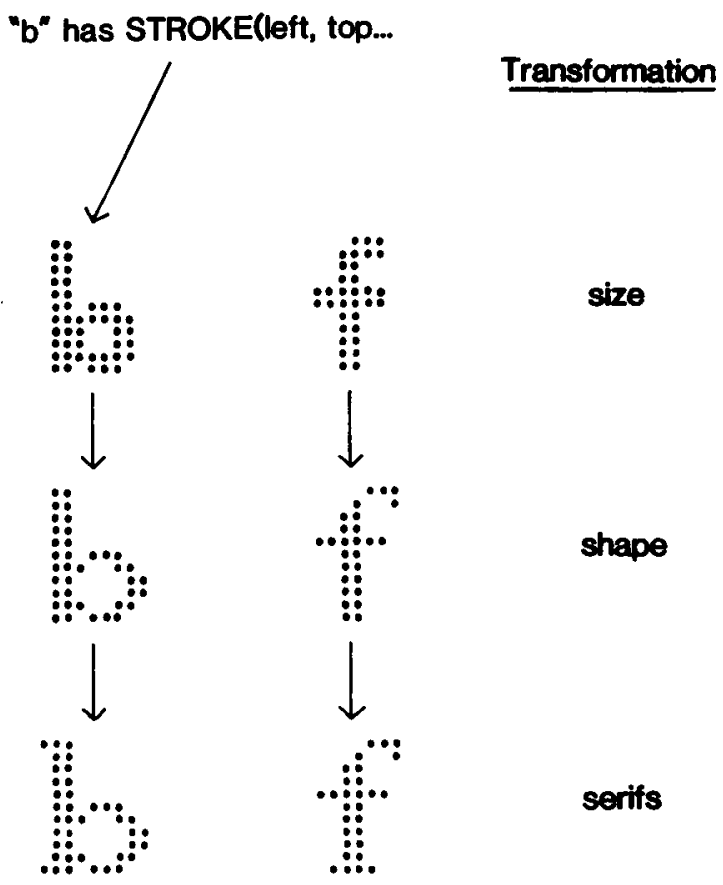

Figure 2 The transformations for two letters of a font 
The serial order of the transformation process is meant to Illustrate constraints between parameters, rather than serial processing. For example, the height and width of letter attr1butes constrains their possible shapes (given a height and width, only certain shapes are possible), and all of these parameters constrain the location of serifs. In general, font-specific properties of letters seem to be closely interrelated (as in a network with many relations), rather than being separate, entirely independent pieces of information.

\section{Bottom-Up Processing and Tuning Effects}

In the present model, newly encountered letters (from a font that has not been seen recently) are recognized by attempting to fit possible attributes and parameter values to the sensory inputs (sensory analyses). There is a family of possible models for describing this bottom-up process. At one extreme, the search space defined by possible attributes and parameter values is unconstrained, and bottom-up processing would involve a search through this enormous space. At the other extreme, the parameters are tightly constrained. For example, the system might assume the parameter values of some prototypical font and change the values only as necessary. However, an intermed1ate model may be more plausible. Perhaps global information (such as spatial frequency or letter size) is extracted early in processing and then used to constrain an educated search through the parameter space. A limited version of this later type of model has been implemented as a computer program that recognizes letters varying in size and shape (Sanockı, 1986b).

Of particular interest here is the idea that the perceptual system tunes itself for a particular font. The descriptions model tunes itself after the recognition of a letter by maintaining parameter values. These values bias or guide subsequent recogn1tion, enabling the system to quickly match attributes and parameters for new letters of the same font. The system also may consider more details of the stımulus and may pool redundant information. As more and more letters of the same font are recognized, the parameter values could be estimated to increasingly accurate degrees, and the gain in efficiency from tuning would increase. Of course, these benefits occur only because letters of a font are systematic If the font were irregular, the system could not become efficiently tuned because different letters would require different parameter values.

\section{Additional Comments}

Many detarls remain to be worked out. In fact, the model may be as useful for raising questions as for providing answers. Also, it should be clear that the model incorporates ideas from more than network theories The idea of general structures with instance-specific variables has been embodied in "schemata" (e.g., Ne1sser, 1976; Rumelhart \& Ortony, 1977) The representation of fonts in terms of parameters has been developed by Knuth (1982), and Palmer (1983) has accounted for an impressive range of perceptual phenomena with a huerarchy of transformational units. A programmable network has been advocated by McClelland (1985), and recent research indicates that perception is influenced by immediately prior processing ep1sodes (e g , Feustel, Shiffrin, \& Salasoo, 1983; Jacoby, 1983).

\section{Testıng the Model}

The model makes two major claims about letter perception One is that letters have abstract, deep-level representations that are invariant across fonts. This claim is supported by consideration of the recognition problem: It seems that at some level, the system has to know that a given letter instance is a member of a general letter-class, irrespective of its font-specific details This requires some type of abstract representation. However, such a claim is difficult to test directly; it may be more feasible to evaluate the claim in terms of its cohesion withın a general model.

The second claim is that the system becomes tuned to the details of a consistent, regular font, and this claim is testable. If the system becomes tuned in this way, then letters of a single font should be perceived efficiently However, the system should not become tuned to just any set of letters In particular, the system could not become efficiently tuned for letters from a mixture of fonts, because they would require different parameter values and could not be represented systematically Therefore, letters from a mixture of fonts should not be perceived as efficiently as letters from a single font.

In contrast to the descriptions model, consider simple feature models, in which the representations consist of independent, unconnected components. Simple feature models cannot predict constrained, systematic tuning effects because there are no mechanısms that could enforce constraints. If tunıng occurs, simple feature models must predict that it would occur for any set of letters or features (not only those conforming to a font), because there cannot be constraints between independent components. These contrasting predictions will be examined in Experiments 1 and 2 on the processing of font-regular and fontirregular typography. Then a further prediction of the descriptions model, pertaining to the relations between representations of different fonts, will be examined in Experiment 3.

\section{Regularity Effects in Letter Perception}

It has been known for some tıme that written material is easler to read when it is of a consistent, regular font than when typographical properties such as font, case, or size vary (e.g., Adams, 1979; Corcoran \& Rouse, 1970, McClelland, 1976; Rudnicky \& Kolers, 1984, Tinker \& Paterson, 1946; for general reviews see Gibson \& Levin, 1975, Tinker, 1963). These results suggest that the perceptual system may tune itself in a systematic manner for a regular font, as the descriptions model predicts. However, the experiments have not been interpreted in light of models of letter recognition, and there are several possible problems with such an interpretation

One problem is that the previous studies have focused on how words are perceived. The stımulı have always consısted primar1ly of words, and the effects of typographic regularity were attributed to units that represent words For example, units that represent word shape would be disrupted whenever size or case varies. To minımize the influence of word units on processing in the present experıments, unrelated strings of consonants were used as stımult. Adams (1979) used unrelated strings and found an advantage for regular- over irregular-font strings, but she created irregular strings by adding letters from atypical fonts to the more typical letters used in the regular condition. 
Therefore, the decrement in the irregular condition could be due to the difficulty of the letters added to that condition, rather than to irregularity per se. McClelland (1976) compared unrelated strings of regular and mixed case and found a small, statistically unreliable advantage for the regular condition. However, in his experiments the regular and mixed strings were intermixed within the same block, and this is not regularity in the present sense If the perceptual system becomes tuned to a font over time, then the font has to be consistent for a number of triais before tuning can occur.

In the present experiments I investigated the effects of font regularity on perceptual processing by comparing regular conditions, in which each string consisted of four letters from the same font, with mixed conditions, in which each string included letters from all of the fonts used in the experiment The task was to determine whether all of the items in a string were letters or If one item was a "nonletter" The nonletters were made from letters by deletıng a part or by adding a part from another letter (examples are shown in Figure 3). Half of the tıme, all four items were letters, and half of the time one of the items was a nonletter The main dependent measure was the subjects' declsion time for all-letter strings

According to the descriptions model, the perceptual system should become tuned to a regular font, resulting in faster perception in regular conditions than in the mixed condition. In an initial experiment, four fonts were used, resulting in four regular conditions and one mixed condition involving all four fonts (Sanockı, 1986a). Subjects were relıably faster in the regular conditions than in the mixed condition, with the advantage for all-letter strings being $165 \mathrm{~ms}$. However, although consistent with the descriptions model, this initual experiment indicates only that the perceptual system can become "set" for certan stımulı (cf. Gibson, 1941; Pachella, 1975), such as a small group of letters or features. To conclude that the system becomes set in a partıcular way for a font of letters, it is necessary to elim!nate these alternative explanations.

Nevertheless, the result is inconsistent with a class of simple feature models. In partıcular, if features were abstract, font-invariant properties, then there would be no reason for a regularity effect, because the system would ignore font-specific detalls. The fact that a regularity effect occurred implies that the perceptual system must be sensitive to font-specific information.

\section{Experıment 1}

One potential problem with the earler experıment (Sanocka, 1986a) and with most other experiments on typographic regularity is that the total number of letter instances becomes greater when the typography is mixed In the earlier experiment, there were only 12 letters in each regular font condition, but when the instances from all four fonts were mixed together in the muxed condition, there were 48 letter instances It is possible that the greater number of letter instances produces the decrement in the mixed condition. For example, the perceptual system might work by matching template-like representations of each 1tem, and the matching process might be completed faster when the set of items is smaller. To correct for this problem, the number of instances was equated between the regular and mixed conditions of Experiment 1. If a regularity effect is obtained, it will indicate that the system does not become set

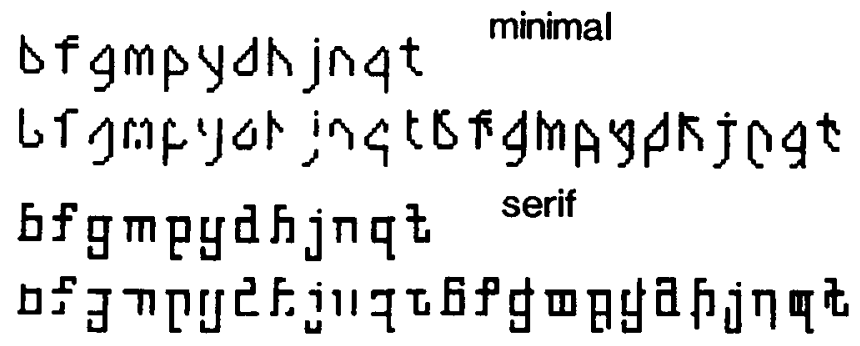

Figure 3 The stimuli used in Experiment 1 (For each font, there is a row of letters and a row of nonletter foils )

for just any small set of letters, and it will be more reasonable to think that the system becomes set for a font.

\section{Method}

Stumul Two of the fonts used in the initial experiment were chosen The fonts had the same 12 letters, which are shown (together with the nonletter foils) in Figure 3 The fonts had a total letter height (from the bottom of a descender to the top of an ascender) of 13 puxels (approximately $070^{\circ}$ of visual angle) The widths varied with the letter but were generally similar across fonts The fonts differed in several ways, including letter shape, the length of terminating segments, and the presence of senfs

For each instance of a letter, two noninstances (nonletter folls) were created-one by erasing a segment of the letter and one by adding a new segment from another letter within the font Care was taken to avoid creating folls that could be letters from another font.

The strings had four items Half of the time all four items were letters, and half of the time one item was a nonletter The letters for all-letter strings were chosen randomly for each position, with the constraint that each letter appear equally often during a block of trials Strings for foll trials were first generated as if they were all-letter strings; then one letter was randomly selected and replaced with one of its two distractors (randomly chosen)

Destgn The central companson was between the regular conditions, in which each string contained letters from a single font, and the mixed condition, in which each string contained two letters from each font For each subject, there were two regular conditions-one for each font-and two mixed conditions In one mixed condition, the first six letters from one font (as in Figure 3) were mixed with the second six letters from the other font, the opposite assignment was used in the other muxed condition Each of the four conditions had an equal number of trials, and the order was counterbalanced across sets of 4 subjects in a Latın square design

Apparatus and procedure Subjects were tested individually in sessions lastung approxımately $40 \mathrm{~min}$ The stımulı appeared on a 9-in video monitor driven by an Apple II microcomputer, in white-on-black dot-matrix letters. A trial began with a warning signal, followed by the simultaneous presentation of the items in the string. The subjects were instructed to press a key indicating yes (they are all letters) or no (there is a nonletter) as quickly and accurately as possible. The stımuli remaned on the screen untll the response was made. If an error was made, the string was redisplayed along with appropriate feedback. Each of the four conditions consisted of 24 practice trials and 48 test trials Short breaks were given every 24 trials

At the start of the session, the subjects identified each of the letters to be used in the expenment The experimenter recorded and then corrected mistakes, which were made on $1.2 \%$ of the occasions At the start of each condition, the 12 letters to be used were presented for an unhmited period of tume for the subject to study. 
Table 1

Reaction Times (RT, in Millseconds) and Percentages of Errors (PE) in Experiment 1

\begin{tabular}{|c|c|c|c|c|c|c|}
\hline \multirow[b]{4}{*}{ Stımulus } & \multicolumn{6}{|c|}{ Condition } \\
\hline & \multicolumn{4}{|c|}{ Regular } & & \\
\hline & \multicolumn{2}{|c|}{ Serif } & \multicolumn{2}{|c|}{ Mınımal } & \multicolumn{2}{|c|}{ Mixed } \\
\hline & $R T$ & $P E$ & $R T$ & $P E$ & $R T$ & $P E$ \\
\hline $\begin{array}{l}\text { All-letter } \\
\text { string }\end{array}$ & 1.425 & 58 & 1,264 & 33 & 1,488 & 52 \\
\hline Foil string & 1,120 & 133 & 1,086 & 183 & 1,237 & 204 \\
\hline
\end{tabular}

Subjects The subjects were 20 introductory psychology students at the University of Wisconsin They received extra course credit for their participation

\section{Results and Discussion}

The main question is whether or not the letters were perceived more quickly in the regular font conditions than in the mixed font condition The mean for correct all-letter responses was $1,344 \mathrm{~ms}$ across the regular conditions and $1,488 \mathrm{~ms}$ in the mixed condition-a regularity effect of $144 \mathrm{~ms}$. This effect was reliable, in an analysis of variance with regularity and order group as factors, $F(1,16)=6.94, p<.05$. $^{\prime}$ This is consistent with the idea that the perceptual system becomes tuned for a set of letters that conforms to the regularities of a font, but not for just any small set of letters. Thus, the results are consistent with the descriptions model and inconsistent with the claim that the regularity effect in the earlser experiment (Sanocki, 1986a) was due to the greater number of letter instances in the muxed condition.

The reaction times for all conditions are reported in Table 1 Generally, the data for foils are of less interest because the process of detectıng folls is not of primary concern here. However, inconsistencies between the data for foils and all-letter strings might indicate experimental artifacts. Accordingly, the data for fols and all-letter strings were compared in an analysis of variance, with response and regulanty as factors. The main effect of regularity was reliable, $F(1,16)=12.53$, and it was consistent across response ( $F<1$ for the interaction). Responses to folls were faster than to all-letter strings, $F(1,16)=30.45$.

The reaction times for the two regular font conditions are also reported in Table 1. The minımal font produced faster responses than the serif font, $F(1,16)=4.72, p<.05$, and this advantage was stronger for all-letter strings than for foils, $F(1$, $16)=6.27, p<.05$. This raises two issues. First, are some fonts "better" than others? Although interesting, this issue is also complex. The goodness of a font may depend in part on how well it matches our knowledge of what letters should look like and on specific task requirements. Because of these complexities, the issue of font goodness is not addressed here The second issue is that, given the slowness of responses to the serif font, one might argue that latencies in the mixed condition are determined solely by the serif font. Thus, the decrement in the mixed condition would be due to the most difficult font, not to regularity. However, this interpretation is refuted in Experiment 2 (and in other unreported experiments) in which reaction time in the mixed condition has been slower than in each of the regular font conditions. In addition, the assumption that both fonts have an effect in the mixed condition receives some support from a further analysis of task performance in Experiment 2.

The error rates are also reported in Table 1 There was an advantage (fewer errors) for the regular conditions, $F(1,16)=$ 14.65 , an effect of response, $F(1,16)=194.98$, and an interaction, $F(1,16)=7.35, p<.05$ For both responses, subjects were more accurate in the regular conditions.

\section{Experiment 2}

As noted earlier, the font regularity effect is inconsistent with simple feature models, in which letters are perceived as sets of abstract, font-1nvariant features. To explain the regularity effect within a simple feature model, it is necessary to assume that font-specific features are involved in letter perception. Fontspecific features may be the only features used in perception, or a combination of font-specific and abstract features may be used. In either case, the regularity effect would have to be explaned in terms of font-specific features, because abstract features would not, by definition, change as the font varies.

However, the same letters appeared in the regular and mixed conditions of Experiment 1, only the assignments of letter instances to conditions differed Therefore, it seems that there would not be a radical change in the features that could be used in the two conditions. In fact, it seems that the only potentially major change between conditions might be that there would be more features in the mixed condition. For example, the ascenders on $b$ and $h$ are normally identical within a font (as in the regular conditions of Experiment 1) However, when a $b$ from one font is mixed with an $h$ from another font, their descenders could differ (as in the mixed condition of Experiment 1), causing a new feature to be added to the total set of features. If, for some reason, processing is slowed when there are more features, then a decrement in the mixed condition would result because of the greater number of features in that condition. Furthermore, the prediction according to this view is that if the total number of features is equated between conditions, then the regularity effect should be greatly dimınıshed

In order to equate the number of font-specific features between conditions, it is necessary to have at least a rough idea of what the features might be The features assumed in simple feature models can be classified almost exhaustively into either of two classes of features-global properties or localized parts. Global properties could not be font specific because they are hıghly abstract For example, Keren and Baggen (1981) assume features such as "facing to the right" (see also, Gibson, 1969); this feature is shared by $K$ and $G$ Obviously, such a feature is not precise enough to be font specific. The other type of feature 1s localized parts (e g, Rumelhart \& Siple, 1974; Townsend \& Ashby, 1982), and these could be font-specific

(There are other possible types of features, but they do not seem consistent with the idea of a simple feature model For

\footnotetext{
'The conventional 05 level of significance was adopted For brevity, alpha levels for effects that are highly significant $(p<01)$ are not reported
} 
example, features could be generalized parts [such as "vertical segment" or "serif"]. However, such features have rarely been included in simple feature models. Moreover, generalızed parts would have to be supplemented by spatial relations [such as "on right of "] in order to distınguish between certain letters [e.g., $b$ from $d]$, and by adding such relations, the model becomes a structural network model Similarly, features might be specific parametric properties [e.g, height $=x$ ]; however, such features are of little use in distınguishing between letters and, accordingly, have rarely [if ever] been included in simple feature models )

In Experıment 2, the number of localızed parts was equated between the mixed and regular conditions by using subsets of letters with mutually exclusive parts. Each font had two subsets of letters One subset had, say, $m$ parts, and the other subset had a different set of $n$ parts. In the regular conditions, both subsets were included, resulting in a total of $m+n$ parts. Similarly, in the mixed conditions, one subset from one font was mixed with the other subset from the other font, also resulting in a total of $m+n$ parts The parts are shown in Figure 4 These parts were selected to be as "major" as possible to reduce the possibility that some features would be divided in half. Of course, it is possible that there are some wrongly divided or overlapping parts, but it seems safe to conclude that the number of parts is at least nearly equal between conditions Together with other aspects of the experıment, this should, according to the simple feature explanation, greatly reduce the size of the regularity effect.

To ensure that subjects had a reasonable amount of exper1ence with the letters and their features, a small set of letters (eight instances in each font) was used, and a large number of trials was run. As before, the subjects could examine the letters at the start of the session and before each condition began In addition, the design was replicated in each of two halves of the session, so that subjects began the second half of the session after over 300 trials of practice. Secondly, in comparison with Experiment 1, the letters were constructed to be more typical

\section{First subset $(b, n, p, r)$ :}
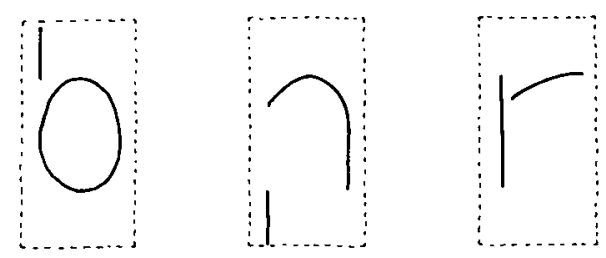

\section{Second subset $(z, v, y, j)$ :}
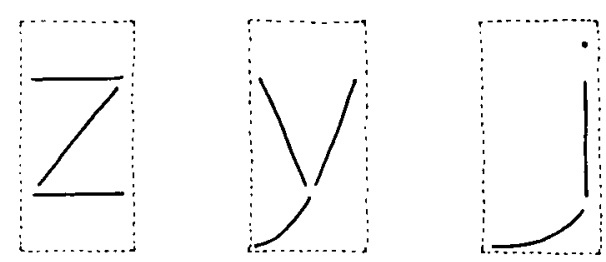

Figure 4 The locations of the features assumed in Experiment 2

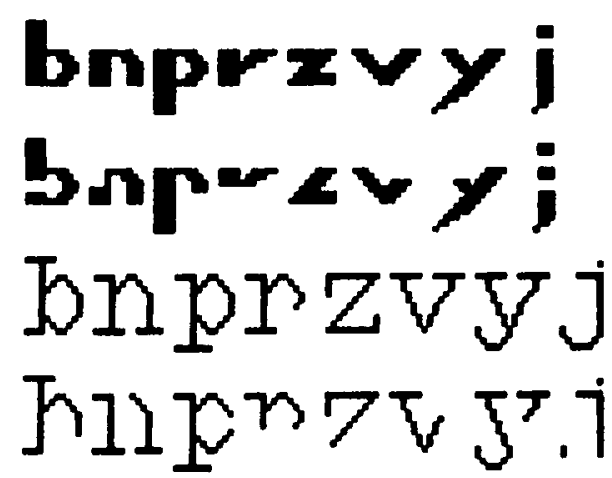

Figure 5 The stımulı used in Experıment 2 (The block font in the first two rows, the serif font in the last two rows )

of natural letters, whereas the folls were constructed to be more obviously different from letters (see Figure 5) Finally, to learn more about performance in the present task, the number of letters in each string was varied, from three to five letters. The effects of string length provide constraints on a model of how the task is performed and of the locus of the regularity effect.

\section{Method}

The two eight-letter fonts are shown, together with their folls, in Figure 5 The total letter height in each of these fonts was 16 pixels. As in the previous experiment, there were two regular font conditions (one for each font), and two mixed conditions, in which one subset from one font was mixed with the other subset (the other four letters) of the other font To examine the effects of practice, there were two replications All four conditions occurred in the first half of the session (for 24 practice trials and 60 test trials each) and then again in the second half of the session (for 12 practice trials and 60 test trials each) As before, subjects named each letter instance before the experiment began (no mistakes were made with the present set of letters) In addition, the entire set of eight letter-instances to be used in a given condition was displayed for an unlımited period before the condition began The order of conditions for a given subject was the same in the first and second halves of the session, the orders were counterbalanced across set of four subjects in a Latın square desıgn

The strings contained three, four, or five items, with each length appearing equally often As in the previous expenment, the assignment of letters to strings was random (within the constraint that each letter appear equally often during a block) However, in the mixed condition of this experiment, there were no constrants on how font should vary within a string, the font of each item was randomly determined ${ }^{2}$ Foil strings always contained only one nonletter, which had an equal probability of being in any position within the string The foils for this experiment were constructed by erasing portions of the letters

Twenty-four new subjects from the same subject pool participated In other respects, the present experiment was similar to Experiment 1

\section{Results and Discussion}

Regularity effects If, as in the simple feature model explanation, processing efficiency depends simply on the number of fea-

\footnotetext{
${ }^{2}$ This means that the probability of the font's varying within a string would increase when more items were chosen for the string and, thus, that three-item stnngs were of a single font more often than were fiveitem strings in the mixed condition However, other experiments (Sanock, 1987) indicate that the size of the regulanty effect is affected only mınımally by whether font varies withın each string or between strıngs
} 
tures in each condition, the letters should be recognized about equally fast in the regular and muxed conditions. On the other hand, the descriptions model predicts an advantage for the regular conditions because the perceptual system should become tuned for letters and letter parts from a single font, but not for letters and letter-parts from a mixture of fonts. The mean for all-letter responses across the regular conditions was $897 \mathrm{~ms}$, whereas the mean in the mixed condition was $1,016 \mathrm{~ms}-\mathrm{a}$ regularity effect of $119 \mathrm{~ms}, F(1,20)=2422$. Thus, the regularity effect is quite strong, even when the number of features was approximately equal between conditions. This is consistent with the idea of a perceptual system that tunes itself for letter parts that conform to the constraints of a font but that does not tune itself for just any set of letter parts. In addition, because the present fonts were more typical of common letters than were the previous fonts, the present results indicate that a regularity effect can be obtained with typical fonts.

Practice had a main effect on all-letter responses; they were $89 \mathrm{~ms}$ faster in the second replication than in the first, $F(1$, $20)=759, p=.01$ In addition, the regulanty effect was somewhat smaller (a regularity effect of $95 \mathrm{~ms}$ ) in the second replication than in the first, but this decrease was not reliable, $F(1$, $20)=129, p>.25$, for the Regularity $\times$ Replication interaction This suggests that modest amounts of practice have, at most, a small influence on the size of the regularity effect.

Subsidiary analyses The reaction times for all main cond1tions are shown in Table 2 . Regularity had a reliable main effect, $F(1,20)=36.40$, but response interacted with regularity, $F(1,20)=4.94, p<.05$. With folls, the regulanty effect was smaller ( $73 \mathrm{~ms}$ ) but still relıable, $F(1,20)=4728$. Responses to foils were faster than responses to all-letter strings, $F(1,20)=$ 13.99. Withın the regular conditions, reaction time to the (present) serif font was faster than to the block font, $F(1,20)=14.68$, but font did not interact with response $(F<1)$. In addition, in this experiment, reaction time to the mixed condition was reliably slower than to either of the regular font conditıons, including the block font. The advantage for the block font over the mixed condition was reliable for all-letter strıngs, $F(1,23)=$ 9169 , and for the data from both responses, $F(1,23)=11.28$.

For errors (Table 2), there was a main effect of response, $F(1$, $20)=50.18$, but not regularity, $F(1,20)=2.78, p>.10$, nor was there an interaction, $F(1,20)=3.72, p>.05$.

String length effects String length had striking effects. First, reaction time increased markedly with string length, $F(2,40)=$

Table 2

Reaction Times ( $R T$, in Milliseconds) and Percentages of Errors (PE) in Experiment 2

\begin{tabular}{|c|c|c|c|c|c|c|}
\hline \multirow[b]{4}{*}{ Stımulus } & \multicolumn{6}{|c|}{ Condition } \\
\hline & \multicolumn{4}{|c|}{ Regular } & & \\
\hline & \multicolumn{2}{|c|}{ Serif } & \multicolumn{2}{|c|}{ Block } & \multicolumn{2}{|c|}{ Mixed } \\
\hline & $R T$ & $P E$ & $R T$ & $P E$ & $R T$ & $P E$ \\
\hline \multicolumn{7}{|l|}{ All-letter } \\
\hline string & 860 & 3.0 & 934 & 1.7 & 1,016 & 23 \\
\hline Foll string & 766 & 98 & 849 & 52 & 880 & 90 \\
\hline
\end{tabular}

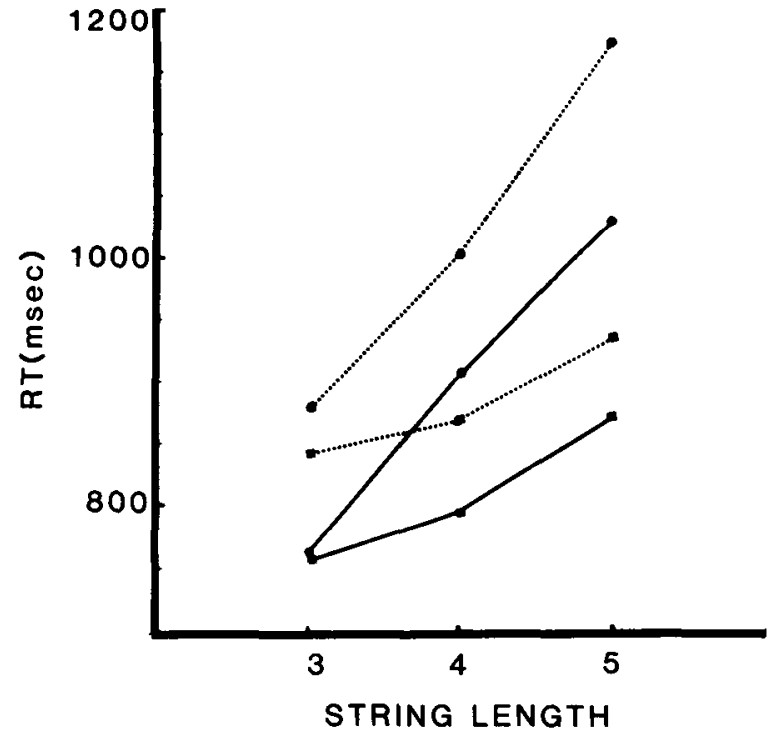

Figure 6 Reaction times as a function of string length in Experıment 2 (The dotted lines are for the mixed condition, and the solid lines are for the regular conditions The circles are for all-letter strings, and the squares are for nonletter strıngs )

82.03. These data are shown in Figure 6 As can be seen, the slopes are constant across string length, but much steeper for all-letter strings ( $138 \mathrm{~ms}$ per additional item) than for foils ( 51 ms per 1tem), $F(2,40)=19.40$ for the interaction. Moreover, the effects of string length and regularity were additive; there is no evidence of an interaction, ${ }^{3} F(2,40)<1$ (see Figure 6) Flnally, although there was an overall difference between fonts in the regular conditions (as reported above), the effects of font and string length were also additive, $F(2,40)=1.06$ for the interaction.

When interpreted withın a general framework provided by previous research and theory on letter perception, the effects involving string length constrain a model of how the present task is performed and of the locus of the regularity effect. The framework assumed here involves three potentially overlapping stages of processing: (a) an initial sensory analysis (often termed feature detection in the literature), (b) an accumulation of information about letters and activation of letter codes (to be refered to as letter activation here), and (c) a decision and/or response process (see, e.g., Erıksen \& Schultz, 1979, Estes, 1978; Lupker, 1979, Massaro \& Schmuller, 1975, McClelland \& Rumelhart, 1981; Pashler \& Badg10, 1985, Townsend \& Ashby, 1982). As in the models cited here, it is assumed that sensory analysıs and letter activation are, for the most part, parallel across the display.

Perhaps the most obvious feature of the data is the large, linear effect of string length and the difference in slope as a function of response. Such a pattern of data is the trademark of a

\footnotetext{
${ }^{3}$ Note that the additivity of string length and regularity should not depend on the fact that in the mixed conditions, three-item strings were of a single font more often than were five-item strings (see Footnote 2) If anything, this fact would increase the size of the regularity effect for long strings, causing an interaction
} 
limited capacity, self-termınatıng process for determınıng the coirect response. This process could be serial or parallel. A serial process might involve scanning the string and searching for a foil If a foil were encountered, the appropriate response would be made immediately, but otherwise the scan would contınue untıl the last letter was evaluated. Such a process would take more time to complete with longer strings because, on the average, more items would be scanned. Also, the slope for nonletter strings would be about half that for all-letter strings because, on the average, about half as many items in a nonletter string would have to be scanned before a response could be made (cf. Sternberg, 1969). A serial scan with focused attention may well be necessary in the present task because, if attention is not focused on each item, features from nearby items may combine with each other and change a nonletter into an illusory letter (e g., Treısman \& Gelade, 1980, Tressman \& Souther, 1986). By evaluating each item in turn, subjects could minimize illusory conjunctions and respond farly accurately

Alternatively, the decision/response process could be parallel, with a limited amount of capacity being distributed among the letter positions (see Townsend \& Ashby, 1983). For example, the process might consist of cycles in which the amount of "noise" (e.g., Krueger, 1978) or, in the present case, "oddness" is counted. The cycles would continue untl the oddness count exceeded a criterion or until the count was clearly less than would be expected if a nonletter were present. Responses would take more time with longer strings because the limited capacity is divided among more letter positions, and the slope for nonletter strings could be less than for all-letter strings because the cycles could terminate as soon as enough oddness is detected.

In either case, it seems that this self-terminating decision process would be the last major process (aside from response initiation and execution). Consider now the effect of regularity, which was constant across (additive with) string length. Additivity implies that two factors affected separate processes; such a conclusion holds in many kinds of models (see Townsend \& Ashby, 1983), uncluding additive-factor models (e.g., Sternberg, 1969) and most possible cascade models (Ashby, 1982; McClelland, 1979) Thus, given that the self-terminating decision process is the last major process and that regularity affects a process separate from the decision process, we can conclude that regularity affects a perceptual process prior to the decision process

Withın the present framework, it is logically possıble that regularity affected either the sensory analysis or the letter activation process However, a considerable amount of previous research is consistent with the assumption that sensory analyses are affected only minımally by situational or task variables (see, e.g., Neısser, 1967, Treisman, in press). Therefore, it seems more reasonable to assume that regularity affected the process by which letter codes are activated

The conclusion that regularity affects the letter activation process receives converging support from experiments in which letter strings were presented briefly for subjects to identıfy, followed by a mask (Sanock1, 1987). In those experiments, robust regularity effects on accuracy were obtained, beginnıng at brief stimulus durations and continuing to asymptote.

Finally, one possible complication in the present interpretation should be noted: It is the difference between the two fonts in the regular conditions. Because the difference was additive with string length, the effect must precede the self-termınating decision stage (by the earlier logic). This means that in the mixed condition, the letter activation process would finısh later for items from the more difficult font than for items from the easier font. The implications of this are not entirely clear. Given a serial decision process, we could assume that the subject begins the serial scan in a focused manner, by focusing on one item and beginning as soon as its representation has stabiluzed. Half of the time, the scan would begin early because the initial item was an easy-font item, and half of the time the scan would begin later because the initial item was a difficult-font item. Because of the slow rate of the scan (138 ms per item), the other items in a string should usually have stable representations by the time the scan gets to them. Thus, the primary effect of font would be on the onset of the scan, and the two fonts would have about the same influence on overall reaction time in the mixed condition. If the self-terminating process was parallel, however, the effects of font would be difficult to determine. The effects may depend on how capacity is distributed as items become ready for the decision process and as decision processing is completed for certain items.

\section{Conclusions}

Experiment 2 supported the descriptions model by showing that a strong regularity effect can be obtained, even when the number of font-specific features is equated between the regular and mixed conditions. In addition, the effect was obtained with typical letters after some practice Finally, the effects of string length constrain a model of how the task is performed and support the claim that regularity affects perceptual processing.

Given the model of task performance, it is possible to consider simple feature models in a more precise way to determine whether there are other ways (in addition to those tested above) that the simple feature model could account for the results. In the present task, it seems that two types of discriminations may be necessary. First, subjects may have identified letters during the self-terminating decision process, if not before in the letter activation process. In simple feature models, identification is easier when the relevant objects have fewer common features and more distinctive features (e.g , Townsend \& Ashby, 1982; Keren \& Baggen, 1981; Tversky, 1977). Therefore, if letter identification is involved in the present task, then simple feature models would predict that, if anything, identification should be easier in the muxed condition (when font differences could add distınctive features) than in the regular conditions (when properties of the font are shared by all targets) The second type of discrimination involved in the present task was between letters and nonletter forls. However, the same letters and folls were used in both the regular and mixed conditions. Therefore, objectively, the ease of discriminatıng between a letter and its foils did not change between conditions. More important, simple feature models have no motivation for predicting that it could change. In sum, this analysis provides no support for simple feature models

\section{General Discussion of Experiments 1 and 2}

The experiments provided strong support for the descriptions model's prediction of systematic tuning effects. Letter perception was faster when the letters were from a consistent, regular 


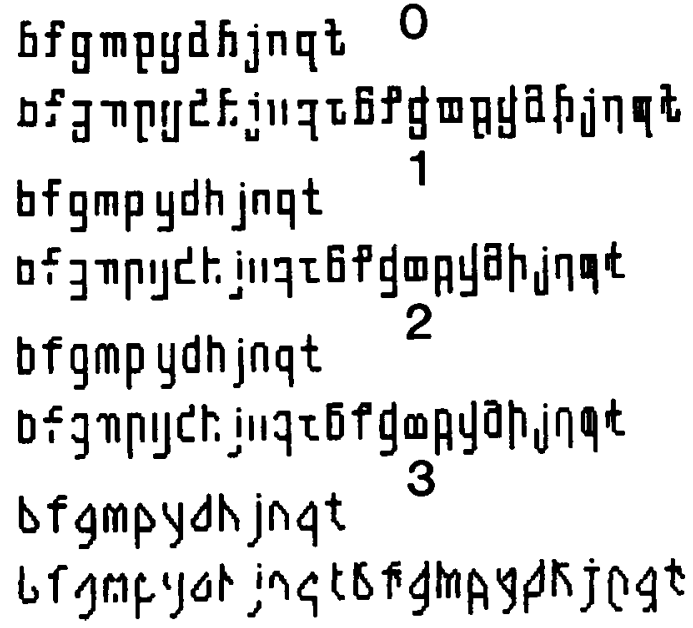

Figure 7 The stımulı used in Experiment 3

font than when the letters were from a mixture of fonts. The experiments were inconsistent with simple feature model explanations based on abstract features and/or font-specific features. One important question, however, concerns the generality of regularity effects. As noted earlier, regularity affects word perception and reading (e.g , Corcoran \& Rouse, 1970; Rudnicky \& Kolers, 1984). In addition, more recent experıments mentioned above indicate that robust regularity effects can be obtained with two important changes in procedure (Sanock, 1987). First, the effect can be obtained when letters are presented bnefly and identification accuracy is measured. Therefore, the requirements of detectung nonletters or making dec1sions are not necessary for the effect. Secondly, the regularity effect can be obtained when font varies in the mixed condition from string to string, so that each string is of only one font. (In the present experiments, font varied within each string.) Therefore, the regularity effect does not depend on the disruption of configural features that might exist with adjacent, same-font letters but not with adjacent, different-font letters.

Two central claims of the descriptions model were supported by the results. First, different letters and letter parts are not completely independent components of the representation; instead, they are components of a representational system in which the details of one letter or letter part are constrained by the detals of other letters and letter parts. A second and related clarm is that font-specific detals are represented and used in letter perception. Although it is not clear how specific the detalls are (not all details need to be represented and used), the potency of font manipulations indicates that at least some font-specific information is used in perception. Presumably, font-specific information could constrain the interpretation of stımulus information and allow additional, redundant information to be gathered and pooled in the identification process

\section{Experiment 3}

Experiments 1 and 2 focused on how the system tunes itself for a single font. However, an important, complementary set of questions concerns how different fonts are processed and how the representation of one font might be related to the represen- tation of other fonts. The descriptions model was designed to recognize letters from many fonts, and it predicts certain systematic relations between the representations of different fonts The purpose of Experiment 3 was to begin exploring these relations while at the same time providing additional information about the source of difficulty in mixed conditions

In the descriptions model, fonts are defined by their parameter values, and different fonts are related to each other because they have the same parameters (only the values differ). In general, fonts that share more parameter values have representations that are more simular to each other, whereas differences between fonts should be some weighted function of parameter differences.

The notion of parameter values can be extended to account for perception in conditions where the font is mixed In particular, different fonts can be percerved by making adjustments in the parameter values. Thus, before a given trial, the parameter values would be withın the range of values for the relevant fonts. When a particular letter is perceived, the values can be adjusted for that letter. If this adjustment process takes time, then processing would take longer in the mixed condition because the parameter values must be adjusted for each letter Presumably, the adjustments would occur at the same tıme for different letter positions (as part of the letter activation process, according to the model developed in Experiment 2). The size of the decrement in the mixed condition should be related to the number of adjustments that must be made for each letter. When the relevant fonts differ on more parameters, more adjustment will be necessary, and the decrement due to muxing (the regularity effect) should be larger.

The purpose of Experıment 3 was to examıne the adjustment explanation by comparing the sizes of the mixing effect for three pairs of fonts. If there is an increase in the size of the effect as the fonts in the mixture become increasingly dissimilar, it would support the idea that the source of difficulty in the mixed conditoon is the need to adjust the representations. Moreover, such a result would support the general assumptions that the represen-

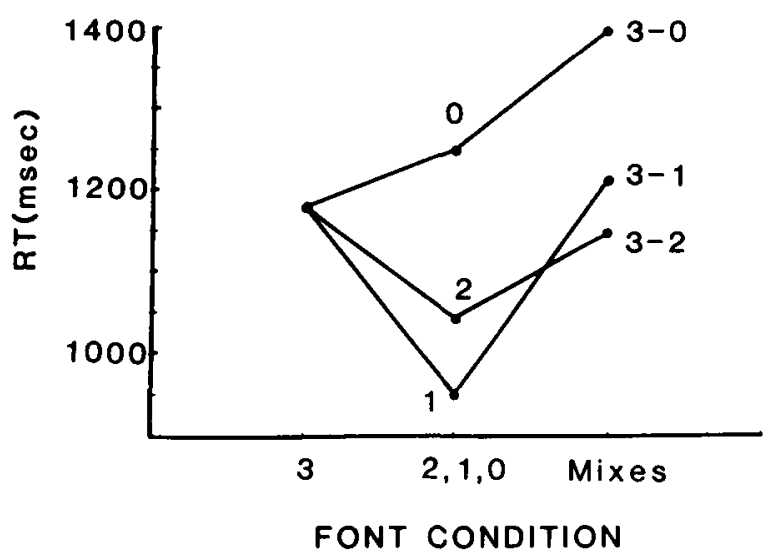

Figure 8 Reaction tımes for all-letter responses in Experıment 3 (Note that the regularity effect for a given mixture corresponds to the difference between the mixed condition [on the right in the figure] and the average of the two regular font conditions, which would be the midpoint of the line connecting the two regular font conditions [left and middle of the figure] ) 
Table 3

Reaction Times (in Milliseconds) for Fotls in Experiment 3

\begin{tabular}{|c|c|c|c|c|c|c|}
\hline \multicolumn{7}{|c|}{ Condition } \\
\hline \multicolumn{4}{|c|}{ Regular } & \multicolumn{3}{|c|}{ Mixed } \\
\hline 0 & 1 & 2 & 3 & $0-3$ & $1-3$ & $2-3$ \\
\hline 1,026 & 868 & 912 & 998 & 1,073 & 1,065 & 999 \\
\hline
\end{tabular}

tatıons of different fonts are systematically related to each other and vary in their degree of similarity.

\section{Method}

Design and stimult The design involved four fonts $(0,1,2$, and 3$)$ Font 3 served as a base font; the other three fonts ( 2 through 0 , respectively) were increasingly different from Font 3 There were three mixed conditions, each involving Font 3 The mixtures, in order of increasing font difference, were Fonts 3 and 2, 3 and 1 , and 3 and 0 There was also a regular condition for each of the fonts, making a total of seven different conditions A subject participated in each condition in an order that was counterbalanced across sets of 7 subjects in a Latın square desıgn

The four fonts are shown in Figure 7 Font 3 was the minımal font from Experiment 2 Font 2 was derived from Font 3 by changing the loop shape, and Font 1 was derived from Font 2 by lowerng the $x$-height and changing the loop shape a bit further Font 0 (the serif font in Exper1ment 2) could then be derived from Font 1 by adding serifs

The strings were always four items in length In the mixed conditions, each string had two items from each font In addition, in the mixed conditions, one subset of six letters (the first or last six in Figure 7) from Font 3 was mixed with the other six letters in the other fonts (resulting in 12 letters in each mixed condition and each regular condition) The subset assignments were counterbalanced across subjects, with 17 subjects receiving one assignment and 18 receiving the other

Procedure and subjects At the start of the experiment, the subjects were told about the task Before each condition began, the subject was given an unlımited period of time to examine the 12 letters to be used in that condition Thirty-five subjects participated, 5 in each order group

\section{Results}

The main concern is the size of the mixing effect (regularity effect) for all-letter strings in the three mixtures. As before, the mixing effect is the difference between a mixed condition and the mean of its corresponding regular font conditions. The prediction was that the mixing effect would be greater when the fonts in the mixture are more different from each other, because more adjustment will be necessary There was a mixing effect

Table 4

Percentages of Errors in Experiment 3

\begin{tabular}{|c|c|c|c|c|c|c|c|}
\hline \multirow[b]{3}{*}{ Stımulus } & \multicolumn{7}{|c|}{ Condition } \\
\hline & \multicolumn{4}{|c|}{ Regular } & \multicolumn{3}{|c|}{ Mixed } \\
\hline & 0 & 1 & 2 & 3 & $0-3$ & $1-3$ & $2-3$ \\
\hline $\begin{array}{l}\text { All letter } \\
\text { Nonletter }\end{array}$ & $\begin{array}{rl}31 & 1 \\
131\end{array}$ & $\begin{array}{l}17 \\
75\end{array}$ & $\begin{array}{r}18 \\
114\end{array}$ & $\begin{array}{r}25 \\
152\end{array}$ & $\begin{array}{r}42 \\
154\end{array}$ & $\begin{array}{r}31 \\
135\end{array}$ & $\begin{array}{r}25 \\
135\end{array}$ \\
\hline
\end{tabular}

Table 5

Font Parameters for the Three Fonts in Experiment 3

\begin{tabular}{lllll}
\hline & \multicolumn{5}{c}{ Font } \\
\cline { 2 - 5 } Parameter & \multicolumn{1}{c}{0} & \multicolumn{1}{c}{1} & \multicolumn{1}{c}{2} & \multicolumn{1}{c}{3} \\
\hline Center height & & & 7 & 7 \\
(C) & $6^{2}$ & 6 & $5 / \mathrm{C}$ & $6 / \mathrm{C}$ \\
Center width & $6 / \mathrm{C}^{\mathrm{b}}$ & $5 / \mathrm{C}$ & $2 / \mathrm{C}$ & $2 / \mathrm{C}$ \\
Top height & $3 / \mathrm{C}$ & $2 / \mathrm{C}$ & $4 / \mathrm{C}$ & $4 / \mathrm{C}$ \\
Bottom height & $4 / \mathrm{C}$ & $4 / \mathrm{C}$ & Seardrop \\
Loop shape & Square & Square & Squarish & Teard \\
Thickness & $1 / \mathrm{C}$ & $1 / \mathrm{C}$ & $1 / \mathrm{C}$ & $1 / \mathrm{C}$ \\
Serifs & Present & None & None & None \\
\hline
\end{tabular}

- The numbers are size units, corresponding to pixels in the present case

${ }^{b}$ Parameters given as fractions are relative to the height of the central square (C)

for each mixture, moreover, it increased in size, being $35 \mathrm{~ms}$, $147 \mathrm{~ms}$, and $180 \mathrm{~ms}$ for mixtures 3-2 through 3-0.

The means for each condition are plotted in Figure 8, with lines connecting a mixed condition with its corresponding regular conditions. To test the reliablity of the increase in the mixing effect, a trend analysis was conducted using the mixing effects for each subject. The increase was reliable, $F(1,28)=$ 13.82 (for the linear trend). This supports the hypothesis that letters in the mixed conditions are perceived as a result of an adjustment process that takes longer when the fonts are more dissımilar.

Subsidiary analyses The foll data are reported in Table 3 Responses to folls were faster than to all-letter strings, $F(1$, $28)=42.72$, and response interacted with condition, $F(6$, $168)=8.65$. The interaction stems mainly from one foll cond1tion: The patterns of means were generally identical across response, except that the 3-0 mixed condition for foils was faster relative to the other conditions. The mixing effects for foils were $44 \mathrm{~ms}, 132 \mathrm{~ms}$, and $61 \mathrm{~ms}$ for mixtures 3-2 through 3-0, respectively. The meaning of this curvilinear relation for folls is not clear.

For error rates (Table 4), there was an effect of condition, $F(6$, $168)=11.03$; response, $F(1,28)=167.24$; and an interaction, $F(6,168)=5.63$. As can be seen from the table, the error rates were higher in the mixed conditions. The mixing effects on error rates mirrored the patterns for reaction tımes. For all-letter strings, the disadvantage for the mixed condition increased across mixtures $(0.3 \%, 1.0 \%$, and $1.4 \%$ for mixtures $3-2$ through 3-0), while there was the curvilinear trend for folls $(0.2 \%, 2.1 \%$, and $12 \%$, respectively)

\section{Discussion}

The results support several types of conclusions. First, the increase in the mixing effect with font difference is consistent with the idea that the source of difficulty in the mixed condition is the need to adjust representations Second, the result is consistent with the idea of a general system that can represent var1ous fonts and in which fonts differ systematically from each other. Below, the description model's representation of the present fonts is described more explicitly. 
Fonts are defined by the values of their parameters, whıch control the transformation from abstract descriptions to fontspecific descriptions. The parameters that control a particular transformation (e.g., size or shape) are similar to a small set of dimensions (e.g , a set of fuzzy features, Oden \& Lopes, 1982, or a multıdımensional space) on which fonts can differ. The present fonts differed mainly on size parameters (e.g., height, width), loop shape, and the presence of serifs. A particular font would be represented within this system as a set of font parameters The representation of each of the four fonts is listed in Table 5

The translation from Font 0 to Font 3 requrred changes in the size parameters, loop shape, and serifs. We would begin by changing the height and the width of the central square. Other parameters, including other size parameters, are defined relative to the size of the central square, and they change in a coordinated manner with it. After the size parameters have been changed, loop shape could be changed and then the serifs. A contrasting, simpler translation would be between Fonts 0 and 1 This translation would require a change of the serif parameter.

Although the font parameters have been treated as a homogeneous set, note that there may be interesting differences between the parameters in their metric properties. For example, size might involve faurly straightforward, contınuous dimensions, but it may be more challenging to arrive at simple quantitative parameters for loop shape (although it does seem to $\mathrm{in}$ volve contınuous dimensions) In contrast to size and shape, the presence of serifs appears to be a more dichotomous dimension or (because big serifs might be different from small serıfs) at least a dımension with a zero value (cf. Garner, 1978; Treısman \& Souther, 1985).

\section{General Discussion}

The main conclusion from the present experiments is that for a font of letters, visual information is represented in a highly structured system that becomes tuned in a specific, detalled way. The evidence was the finding of regularity effects' The system becomes tuned to efficiently process letters withın a regular font, but it cannot become finely tuned for small sets of letters or features from a mixture of fonts. The representational system is able to adjust itself for different fonts (as Experiment 3 indicates), but this adjustment process takes time

The results argue against simple feature models because those models have no way to account for the systematic constraints on tuning. In simple feature models, each feature is an independent component of the representation, so there is no way that characteristics of one feature (1.e., its font) can constrain the representation of another feature. Logical problems that stem from the lack of representational power in simple features models have been pointed out previously (e g., Massaro \& Schmuller, 1975; Oden, 1979; Palmer, 1978, Pinker, 1984, Rock, 1983, Townsend, Hu, \& Evans, 1984). The descriptions model provides an alternative approach to the problem of how familar objects are recognized, and the experımental strategy of manipulatıng stımulus regularities may provide many useful constraints on the descriptions model and other powerful network models

\section{References}

Adams, M J (1979) Models of word recognition Cognitive Psychology, $11,133-176$

Ashby, F G. (1982) Deriving exact predictions from the cascade model Psychological Review, 89, 599-607

Corcoran, D W J , \& Rouse, R O (1970) An aspect of perceptual organization involved in reading typed and handwritten words $Q u a r$ terly Journal of Experimental Psychology, 22, 526-530

Eriksen, C W, \& Schultz, D W (1979) Information processing in visual search A continuous flow conception and experimental results Perception \& Psychophysics, 25, 249-263

Estes, W K (1978) Perceptual processing in letter recognition and reading In E C Carterette \& M P Friedman (Eds), Perceptual processing (pp 163-220) New York Academic Press

Feustel, T., C, Shiffrin, R M , \& Salasoo, A (1983) Epısodic and lexıcal contributions to the repetition effect in word identification Journal of Experimental Psychology General, 112, 309-346

Garner, W R (1978) Aspects of a stımulus Features, dımensıons, and configurations In E H Rosch \& B B Lloyd (Eds), Cognition and categorization (pp 99-133) Hillsdale, NJ Erlbaum

Gibson, J J (1941) A critical review of the concept of set in experimental psychology Psychologual Bulletin, 38, 781-817

Gibson, E J (1969) Principles of perceptual learning and development New York Appleton-Century-Crofts

Gibson, E J, \& Levin, H (1975) The psychology of reading Cambridge, MA MIT Press

Gilmore, G C (1985) Letters are visual stımul $A$ comment on the use of confusion matrices Perception \& Psychophysics, 37, 389-390

Jacoby, L L (1983) Perceptual enhancement Persistent effects of an experience Journal of Experimental Psychology Learning. Memory, and Cognition, 9, 21-38

Keren, G, \& Baggen, S (1981) Recognition models of alphanumenc characters Perception \& Psychophysics, 29, 234-246

Knuth, D E (1982) The concept of a meta-font Visible Language, 17. 3-27

Krueger, L E (1978) A theory of perceptual matching Psychological Review, 85, 278-304

Lupker, S J (1979) On the nature of perceptual information during letter perception Perceptıon \& Psychophysics, 25, 303-312

Massaro, D W, \& Schmuller, J (1975) Visual features, preperceptual storage and processing time in reading In D W Massaro (Ed), Understanding language (pp 207-239) New York Academic Press

McClelland, J L (1976) Prelımınary letter identıficatıon in the perception of words and nonwords Journal of Experimental Psychology Human Perception and Performance, 2, 80-91

McClelland, J L (1979) On the time relations of mental processes An examination of systems of processes in cascade Psychological Revlew, 86, 287-330

McClelland, J L (1985) Putting knowledge in its place A scheme for programming parallel processing structures on the fly Cognitive Sctence, 9, 113-146

McClelland, J L, \& Rumelhart, D E (1981) An interactive model of context effects in letter perception Part 1 An account of basic findings Psychological Review, 88, 375-407

Minsky, M A (1975) A framework for representıng knowledge In P H Winston (Ed), The psychology of computer vision (pp 211280) New York McGraw-Hill

Neisser, U (1967) Cognitive psychology New York Appleton-CenturyCrofts

Neisser, U (1976) Cognitıon and realtty San Francisco Freeman

Oden, G C (1979) A fuzzy logical model of letter identification Journal of Experimental Psychology Human Perception and Performance, 5, 336-352

Oden, G C , \& Lopes, L L (1982) On the internal structure of fuzzy subjective categories In R R Yager (Ed), Recent developments in 
fuzzy set and possibllity theory (pp 75-83) Elmsford, NY Pergamon Press

Pachella, R G (1975) The effect of set on the tachistoscopic recognitıon of pictures In P M A Rabbit \& S Dornic (Eds), Attentıon \& performance $V$ (pp 136-155) New York Academic Press

Palmer, S E (1977) Hierarchical structure in perceptual representation Cognutlve Psychology, 9, 441-474

Palmer, S E (1978) Fundamental aspects of cognitıve representation In E Rosch \& B Lloyd (Ed.), Cognttıon and categorizatıon (pp 259303) Hillsdale, NJ Erlbaum

Palmer, S E (1983) The psychology of perceptual organization A transformational approach In J Beck, B Hope, \& A Rosenfeld (Eds), Human and machine vision, (pp 269-339) New York Academic Press

Pashler, H , \& Badgo, P C (1985) Visual attention and stimulus ident1fication Journal of Expertmental Psychology Human Perception and Performance, $11,105-121$

Pinker, S (1984) Visual cognition An introduction Cognition, 18, 1-63

Rock, (1983) The logic of perception Cambridge, MA MIT Press

Rudnıcky, A I , \& Kolers, P A (1984) Sıze and case of type as stımulı in reading Journal of Experimental Psychology Human Perception and Performance, 10, 231-249

Rumelhart, D E \& Ortony, A (1977) The representation of knowledge in memory In R C Anderson, R J Spiro, \& W E Montague (Eds), Schooling and the acquisttion of knowledge (pp 99-135) Hillsdale, NJ Erlbaum

Rumelhart, D E , \& Siple, P (1974) Process of recognizıng tachıstoscopically presented words Psychological Review, 81, 99-118

Sanockı, T (1986a) Visual knowledge underlying letter perception $A$ font-specific approach Unpublished doctoral dissertation, University of Wisconsin, Madison

Sanockı, T (1986b) Toward a tuneable system for recognizing letters of any type font Unpublished manuscript
Sanock1, T (1987). Constraints on the process of letter recognition The effect of font regularity Unpublished manuscript

Sternberg, S (1969) Memory scanning Mental processes revealed by reaction-tıme experıments American Sclentist, 57, 421-457

Tinker, M A (1963) Legibility of print Ames, IA Iowa State Unıversity Press

Tinker, M A., \& Paterson, D G (1946) Readability of mixed type forms Journal of Applied Psychology, 30, 631-637

Townsend, J T, \& Ashby, F G (1982) Experimental test of contemporary mathematical models of visual letter recognition Journal of $E x$ perimental Psychology Human Perception and Performance, 8, 834864

Townsend, J T., \& Ashby, F. G. (1983) Stochastic modeling of elementary psychological processes New York Cambridge Unıversity Press

Townsend, J T, Hu, G G, \& Evans, R J. (1984) Modeling feature perception in brief displays with evidence for positive interdependencies Perception \& Psychophysics, 36, 35-49

Treisman, A (in press) Properties, parts, and objects In $\mathrm{K}$ Boff, $\mathrm{L}$ Kaufman, \& J Thomas (Eds), Handbook of perception and human performance

Treisman, A., \& Gelade, G (1980). A feature-integration theory of attention Cognitive Psychology, 12, 97-136

Treisman, A , \& Souther, J (1985) Search asymmetry A diagnostic for preattentive processing of separable features. Journal of Experimental Psychology General, 114, 285-310

Tressman, A , \& Souther, J (1986) Illusory words The roles of attention and top-down constraints in conjoining letters to form words Journal of Experimental Psychology Human Perception and Performance, 12, 3-17

Tversky, A (1977) Features of similarity. Psychological Review, 84, 327-352.

Received May 27, 1986

Revision received November 10, 1986 